\title{
Host-member misperceptions about what others expect of immigrants: The role of personal attitudes, voting behaviour, and right-wing authoritarianism
}

\author{
Zoe Leviston, ${ }^{1}$ (D) Jana M. Coenen, ${ }^{2}$ and Justine Dandy ${ }^{1}$ \\ ${ }^{1}$ School of Arts and Humanities, Edith Cowan University, Perth, Western Australia, Australia, and ${ }^{2}$ University of \\ Osnabrück, Osnabrück, Germany
}

Concordant acculturation expectations and preferences between a host society and its immigrants are important for social cohesion. But perceptions of others' attitudes are often distorted, and may extend to intracultural misperceptions about what others in one's own society expect for immigrants. We test whether attitudinal misperceptions operate in the context of host-members' acculturation expectations of immigrants - preferences about whether newcomers should embrace the majority culture, or maintain their own cultural heritage. Further, we test whether the conservative dimension of right-wing authoritarianism (RWA-C) drives both personal acculturation expectations and distortions about what others expect. We surveyed a representative sample of 2,013 Australian citizens about their own acculturation expectations for immigrants and their perceptions of the expectations of the host society in general. People significantly overestimated the extent to which fellow host society members expect immigrants to embrace the host culture, and underestimated expectations that immigrants retain their own culture. Voting behaviour and RWA-C were related to personal acculturation expectations and to perceptions of host society consensus with their own views (self-other discrepancy). Moreover, personal acculturation expectations mediated the link between RWA-C and perceived self-other discrepancy. The psychological bases of these misperceptions, and their potential ramifications for immigrants, are discussed.

Keywords: acculturation, multiculturalism, pluralistic ignorance, right-wing authoritarianism, social perception, voting behaviour.

Acculturation describes the process of cultural change when two or more groups "come into continuous, firsthand contact, with subsequent changes in the original cultural patterns of either or both groups" (Redfield, Linton, \& Herskovits, 1936, p. 149). The process is not passive, but one in which all groups engage in intercultural strategies and have expectations about how the other group(s) will behave and adapt to ongoing intercultural contact (Berry, 2005; Bourhis, Moise, Perreault, \& Senecal, 1997). According to Berry (2005), when viewed from an immigrant's perspective, these strategies are determined by two dimensions: the extent to which they desire to maintain their heritage and culture, and the extent to which they seek to interact with other cultural groups. Others have interpreted the second dimension as the extent to which there is a desire to adopt the host culture, which has been shown to have a similar pattern

Correspondence: Zoe Leviston, 270 Joondalup Drive, Joondalup, Perth, WA 6027, Australia. E-mail: z.leviston@ecu.edu.au

Received 10 July 2019; revision 13 March 2020; accepted 17 April 2020. of relationships with key variables such as well-being (Berry \& Sabatier, 2011). These strategies can be considered acculturation preferences. A more recent research focus has been the impact of the policies, practices, and attitudes of the host society, and specifically, host community members' acculturation expectations (e.g., Haugen \& Kunst, 2017; Horenczyk, JasinskajaLahti, Sam, \& Vedder, 2013).

The host community's acculturation expectations of immigrants are important for cohesive community outcomes because they are a critical component of mutual acculturation, the two- (or multi-) way dynamic between groups in intercultural contact. In particular, concordance of immigrant preferences and host community expectations is associated with positive outcomes for immigrants and intergroup relations in general (Arends-Tóth \& van de Vijver, 2003; Bourhis et al., 1997; Grigoryev, van de Vijver, \& Batkhina, 2018; Navas et al., 2005). Perceptions of concordant preferences and expectations between immigrants and the host society produce positive attitudinal outcomes among host society members (Matera, Stefanile, \& Brown, 2015), while perceptions of discord can have detrimental effects on immigrants' 
well-being and increase perceptions of intergroup threat in host society members (Kunst \& Sam, 2013; Roccas, Horenczyk, \& Schwartz, 2000; Rohmann, Piontkowski, \& van Randenborgh, 2008; Zagefka \& Brown, 2002).

Perceptions about the expectations of others might not always be accurate, however. For instance, immigrants can sometimes misperceive what the host society expects of them, and conversely, the host society might misperceive the preferences of the immigrants (Rohmann et al., 2008; Ward \& Masgoret, 2018). We argue that such inaccuracies about others' expectations may extend to within-group misperceptions of host society members; that is, host society members may misperceive what others in the host community expect of immigrants. The implications of such misperceptions may be twofold. First, they may serve to entrench marginal beliefs that are falsely assumed to enjoy broad social support. Second, they may signal false social normative information to host society members about what society expects of immigrants, and to immigrants about what is expected of them.

Here, for the first time, we investigate how host society members perceive the immigrant acculturation expectations of their fellow society members. We examine whether these perceptions are accurate, what drives these perceptions (and misperceptions), and how perceptions relate to personal acculturation expectations. Specifically, we investigate whether desire for ingroup and outgroup conformity underlies people's misperceptions. In so doing, we draw upon several important social psychological constructs that influence the construal of social normative information, notably false consensus and pluralistic ignorance effects. These have been overlooked in past acculturation research. In the following sections, we provide an account of these social perception biases, and examine how they might relate to intercultural relationships. We conclude by hypothesising several pathways through which individual-level differences and misperceptions of others' expectations will relate to personal acculturation expectations.

\section{Misperceptions About Others}

Perceptions about others' attitudes are important; people often look to others to help determine what to think and do (Mullen et al., 1985). Yet people are often poor judges of others' attitudes, and perceptual inaccuracies have implications at individual and collective levels (Robbins \& Krueger, 2005). For instance, where one mistakenly thinks their personal attitude is widely shared (a false consensus effect), an initial attitude can be more resilient to change (Ross, Greene, \&
House, 1977). Conversely, where people underestimate the amount of support their own attitude enjoys (a pluralistic ignorance effect), people can be less inclined to express that attitude in a social context, in turn reinforcing social distortions about the attitudes of others (Geiger \& Swim, 2016; Noelle-Nuemann, 1974).

There are several theoretical accounts of why people misperceive others. A cognitive availability perspective argues that false consensus occurs because we more easily recall instances of similarity than dissimilarity with our own position, because we frequently associate with people who share common attitudes (Marks \& Miller, 1987). Moreover, our own attitude serves as an anchor from which we insufficiently adjust, as we lack the informational database about other people's thoughts while being privy to our own (Kruger, 1999). This perspective assumes anchoring effects are universal. But misperceptions about others are often not uniform; for instance, false consensus effects are more pronounced for those holding racially prejudiced attitudes (Watt \& Larkin, 2010), unscientific opinions (Leviston, Walker, \& Morwinski, 2013), and attitudes representing the (numerically speaking) minority position (Sanders \& Mullen, 1983).

An alternative explanation is that misperceptions such as the false consensus effect have inherent functional value. This account of social perception suggests that people may misperceive the views of others in order to bolster perceptions of social support, maintain or restore one's self-esteem, or reduce tension aroused by dissonant attitudes and behaviours. Such "motivated" cognition is thought to occur in circumstances where one is uncertain about the "correctness," popularity, or moral acceptability of one's position (Marks \& Miller, 1987). Under such conditions, it may be functional to exaggerate similarity with others in order to augment social belongingness (Morrison \& Matthes, 2011; Mullen et al., 1985; Suls, Wan, \& Sanders, 1988).

Similar to false consensus, pluralistic ignorancewhereby most people privately reject something (e.g., racially prejudiced attitudes) but incorrectly infer that others do not-arises from motivational biases in information processing, but social and cultural processes are also critical. Information sources, such as social and political groups and the media, provide indicators on which to base estimates of public sentiment. But these sources can also provide misleading or false information cues, such as through systematic biases in media reporting, in turn compounding individual motivational biases about the popularity of certain opinions (Noelle-Nuemann, 1974; Shamir \& Shamir, 1997). 


\section{Misperceptions and Intercultural Relationships}

There is evidence that misperceptions about others extend to perceptions of national sentiment about immigration and multiculturalism, and that this is tied to political orientation and authoritarian dispositions. Pedersen, Griffiths, and Watt (2008) found that, as attitudes toward outgroups-Aboriginal Australians and asylum seekers-became increasingly negative, false consensus with one's own opinion linearly increased. This is consistent with the theoretical literature suggesting false consensus operates to legitimise marginal attitudes. Guimond, de la Sablonnière, and Nugier (2014) found pluralistic ignorance effects in the personal attitudes of French respondents toward multiculturalism and assimilation. Here, attitudes differed significantly across the political spectrum, with left-wing affiliates tending to endorse multiculturalism and reject assimilation, while reverse tendencies were evidenced for right-wing affiliates. Despite these group-based differences, people from all political affiliations perceived the general national sentiment as aligned with the personal views of extreme right-wing affiliates. That is, Guimond et al. found a failure to recognise the broader support that multiculturalism privately enjoys. These findings suggest that false consensus and pluralistic ignorance effects should operate in the context of host community expectations about immigrant acculturation. While Guimond et al.'s findings can be understood in a French context, we argue the current Australian context is ripe for pluralistic ignorance effects to emerge. As elsewhere, Australia is experiencing a resurgence of populism, typified by divisive debate about immigrants. Attendant to this, a prominent section of the commentariat (given frequent airtime in the name of media "balance") has employed increasingly populist rhetoric to warn "mainstream Australia" about the perils of multiculturalism (Leviston, Dandy, Jetten, \& Walker, 2020). This context supplies the necessary conditions for the informational cues on which people base estimates of public sentiment to become distorted (NoelleNuemann, 1974).

Misperceptions have also been found to relate to individual-level traits, including Right-Wing Authoritarianism (RWA). For instance, Grigoryev et al. (2018) found that RWA influenced host society members' perceptions of the acculturation preferences of immigrants, promoting higher perceived discordance between host expectations and immigrant preferences. RWA is itself associated with antagonistic views toward ethnic minorities (Oyamot, Fisher, Deason, \& Borgida, 2012; Strube \& Rahimi, 2006) and with a desire that immigrants assimilate or conform to the dominant culture (Grigoryev, Batkhina, van de Vijver,
\& Berry, 2019; Thomsen, Green, \& Sidanius, 2008). This is unsurprising; an underpinning of RWA is the desire for conformity and coherence to group norms. Duckitt, Bizumic, Krauss, and Heled (2010) conceptualise and cross-culturally validate RWA as a tripartite construct of social attitudes expressing three distinct motivational goals or values: Authoritarianism, Traditionalism, and Conservatism. Each is thought to represent related but different strategies for achieving collective security. The last of these dimensions, Conservatism, may be pertinent to social misperceptions; Duckitt et al. (2010) define it as the opposition to changes in the social status quo, and the favouring of uncritical and obedient support for existing societal or group authorities. Motivational goals centre on the maintenance of social order, harmony, and consensus in society, and stem from threats to this order and consensus, including outgroups who embody such threats (Duckitt et al., 2010).

Hence, RWA-Conservatism (RWA-C) should relate to acculturation expectations in several ways. First, it should translate to a desire for ingroup consensus; that is, a desire that other host country members share one's acculturation expectations, such that social order and consensus are maintained. Second, it should translate to a desire for outgroup conformity; that is, that immigrants conform to the status quo by embracing a host country's culture and dispense with their own. Moreover, the strong expectations of outgroup conformity prompted by RWA-C should also increase the need for the legitimacy of one's position, which may result in (mis)perceptions of greater host society accordance with one's own acculturation expectations (or conversely, lower perceived discrepancy between oneself and others).

\section{The Current Study}

We suggest misperceptions about others' attitudes will operate in the context of perceived acculturation expectations of host society members, by host society members. These misperceptions will be associated with individuals' political affiliations (Guimond et al., 2014) and levels of RWA-C. Moreover, we suggest these individual-level differences and personal acculturation expectations will combine to influence one's perception of the discrepancy between one's own expectations and those of the broader host society. We hypothesise the following:

H1: Personal acculturation expectations will relate to political voting behaviour and to RWA-C, with right-wing voters and those higher on RWA-C having lower cultural maintenance expectations 
and higher cultural adoption expectations for immigrants than left-wing voters and those lower on RWA-C.

H2: People will significantly underestimate their host society's cultural maintenance expectations, and significantly overestimate their host society's cultural adoption expectations.

H3: There will be lower discrepancy between personal acculturation expectations and perceptions of the host society's acculturation expectations ("perceived selfother discrepancy") for right-wing voters and for people higher in RWA-C.

H4: Personal acculturation expectations will mediate the influence of RWA-C on perceived self-other discrepancy.

The unique contributions of these investigations will be to replicate the findings of previous research on misperception in the context of host society acculturation expectations $(\mathrm{H} 1-\mathrm{H} 3)$, and to elucidate whether desire for ingroup and outgroup conformity can explain these misperceptions (H4).

\section{Method}

\section{Participants and Procedure}

An online survey was administered in July 2018 to 2,013 Australian citizens. The research was undertaken in accordance with Australian national Ethical Human Research Policies and with the APA's Code of Conduct. The study received ethical approval from Edith Cowan University's Human Research Ethics Committee. Respondents were recruited through the online recruitment company Qualtrics. Participants received small reimbursements for their time, including points toward shopping vouchers, gift cards, and frequent flyer points. Sampling was stratified by age, gender, and location to maximise representativeness. A large, nationally representative sample allows for realistic comparisons to be made between perceptions of the host nation's views and the actual views of the Australian population. Comparable percentages of men $(47.3 \%)$ and women $(52.0 \%)$ completed the survey (with $0.7 \%$ transgender or preferring to self-describe). Participants ranged in age from 18 to 88 years $(M=46.32 ; S D=16.98)$. When asked to self-describe their ethnicity, $64.8 \%$ described themselves as "Australian." The most commonly reported other ethnic descriptors were Chinese $(2.6 \%)$, Indian (1.8\%), New Zealander (1.6\%), and Italian (1.6\%).

\section{Measures}

Personal acculturation expectations. Acculturation expectation measures were taken from Leong (2008), drawing from existing models of acculturation (Berry, 1997; Bourhis et al., 1997). One item assessed the degree of support for the view that immigrants maintain their culture (hereafter labelled "maintenance expectations"): "Immigrants to Australia should do more to preserve their heritage culture and customs"; one item assessed the degree of support for the view that immigrants adopt the culture of the host society (hereafter labelled "embrace expectations"): "Immigrants should do more to embrace Australian culture and customs." Responses were on a 7-point Likert scale, from 1 (strongly disagree) to 7 (strongly agree).

Perceived acculturation expectations. Estimates of the host society's acculturation expectations were assessed using the same statements as for personal acculturation expectations, with the following introductory statement: "To what extent do you think Australians in general would agree with the following statements." Responses were on the same 7-point Likert scale.

Perceived self-other discrepancy. To determine the discrepancy between participants' personal acculturation expectations and their perception of the host society's expectations, the absolute difference between personal and perceived acculturation expectations measures was calculated. Lower scores indicate a greater degree of perceived consensus between one's own view and that of the host society, with higher scores indicating a greater degree of perceived self-other discrepancy.

Voting behaviour. Participants were asked which political party they had voted for in the last Australian federal election. A total of $28.8 \%$ selected "Labor" (a centre left-wing major party), $29.9 \%$ selected either the Liberal Party $(27.1 \%)$ or the National Party $(2.8 \%)$ who together form the LNP (a centre right-wing major coalition party), $8.8 \%$ selected "The Greens" (a left-wing minor party), and $5.8 \%$ selected "One Nation" (a right-wing minor party). The remainder selected either "Independent" (5.5\%), "Other" $(3.5 \%)$, "Did not vote" $(11.1 \%)$, or "Prefer not to say" (6.6\%). The results closely reflect the House of Representative results of the 2016 Australian federal election (Australian Electoral Commission, 2016).

Right-Wing Authoritarianism-Conservatism. The 6-item Duckitt et al. (2010) short-form Right-Wing Authoritarianism-Conservatism scale was used to measure people's desire for social conformity and consensus. An example item is "What our country needs most is discipline, with everyone following our leaders in 
Table 1

Means, Standard Deviations, and One-Way ANOVA Results Comparing Personal Acculturation Expectations by Voting Behaviour

\begin{tabular}{|c|c|c|c|c|c|c|}
\hline Personal Expectations & Greens & Labor & LNP & One Nation & $F(3,1,472)$ & $\eta^{2}$ \\
\hline Maintenance expectations & $4.19(1.14)_{\mathrm{a}}$ & $4.08(1.15)_{\mathrm{a}, \mathrm{b}}$ & $3.87(1.44)_{\mathrm{b}}$ & $3.09(1.72)_{\mathrm{c}}$ & $17.59 * *$ & .03 \\
\hline Embrace expectations & $4.71(1.32)_{\mathrm{d}}$ & $5.44(1.28)_{\mathrm{c}}$ & $5.76(1.18)_{\mathrm{b}}$ & $6.33(1.11)_{\mathrm{a}}$ & $51.22 * *$ & .09 \\
\hline
\end{tabular}

Note.. Mean scores with different subscripts are significantly different on the basis of Tukey's HSD test.

** $p<.001$.

unity." Responses were recorded on a 5-point Likert scale $(\alpha=.72)$.

\section{Results}

Personal support for immigrants to maintain their cultural heritage, "maintenance expectations" (ME; $M=3.97, \quad S D=1.46$ ), was significantly lower than support for immigrants to adopt the majority culture, "embrace expectations" (EE; $M=5.48, S D=1.32$ ), $t(2,012)=-32.03, p<.001$ (two-tailed), $\eta^{2}=.25$. The two acculturation expectations were significantly but weakly negatively correlated $(r=-.17, p<.001)$.

\section{Hypothesis 1}

One-way ANOVAs revealed significant differences in personal acculturation expectations based on voting behaviour (Table 1), with ME endorsed at significantly higher rates by Greens voters than LNP voters, with Labor voter endorsement between, though not significantly different from, that of Greens and LNP voters.
One Nation voters scored significantly lower on ME than every other voting group. Endorsement of EE differed significantly for each voting behaviour group, with One Nation highest in endorsement, followed by LNP voters, Labor voters, and Greens voters.

There was a small but significant negative correlation between RWA-C and ME $(r=-.18, p<.001)$, and a medium and significant positive correlation between RWA-C and EE $(r=.40, p<.001)$.

Hypothesis 1 is supported.

\section{Hypothesis 2}

Paired-sample $t$-tests revealed participants' estimates of the host society's ME $(M=3.73, S D=1.56)$ were significantly lower than actual $\mathrm{ME}(M=3.97, S D=1.46), t$ $(2,012)=8.50, p<.001$ (two-tailed), $\eta^{2}=.03$. Similarly, participants' estimates of the host society's EE $(M=5.75$, $S D=1.22)$ were significantly higher than actual $\mathrm{EE}$ $(M=5.48, S D=1.32), t(2,012)=-10.89, p<.001$ (twotailed), $\eta^{2}=.06$. Hypothesis 2 is supported.

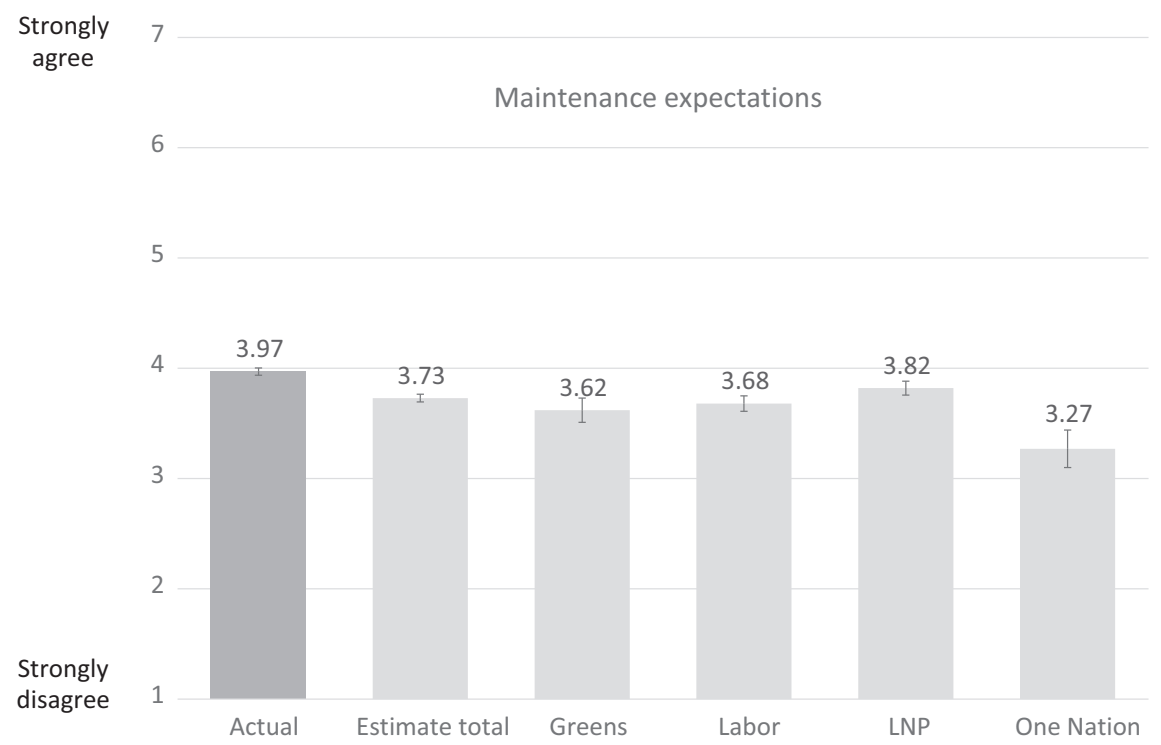

Figure 1 Actual and estimated preferences for maintenance expectations by political voting behaviour. 


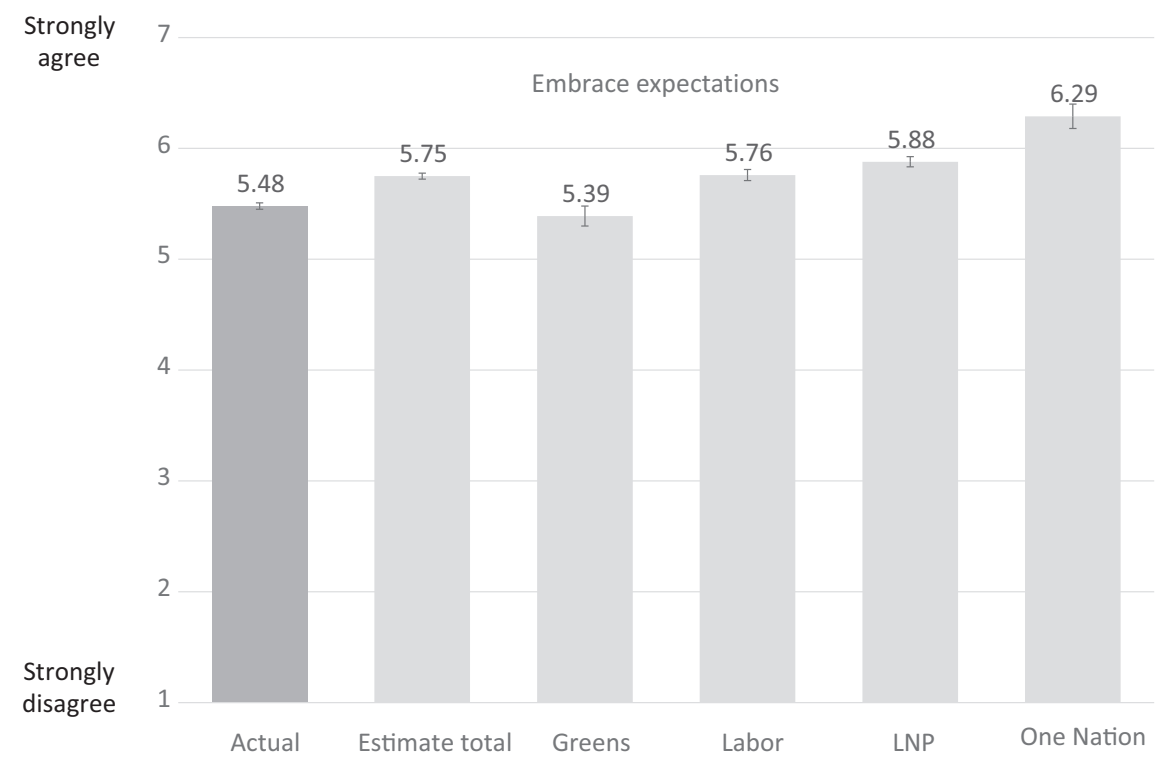

Figure 2 Actual and estimated preferences for embrace expectations by political voting behaviour.

All voting groups significantly underestimated actual ME (Figure 1), and significantly overestimated actual EE, with the exception of Greens voters (Figure 2). One Nation voters' estimates departed furthest from actual means, suggesting these voters were least accurate in their assessments of host society expectations. Follow-up one-way ANOVAs revealed significant differences in estimates of host society's ME based on voting behaviour (Table 2), with ME estimated as significantly higher by LNP voters than One Nation voters, but with no other significant differences between voting groups. Estimates of host society's EE differed significantly based on voting behaviour, with EE estimated as significantly higher by One Nation voters than all other voting groups, followed by LNP and Labor voters, both of whom had significantly higher estimates of EE than Greens voters.

An accuracy score was computed to signify the absolute difference of estimates of others' acculturation expectations from actual acculturation expectations, with lower scores indicating greater accuracy (ME: $M=1.20$, $S D=1.02 ; \quad \mathrm{EE}: \quad M=1.08, \quad S D=0.63) . \quad$ One-way ANOVAs revealed One Nation voters were significantly less accurate in their estimates of the host society's ME than all other voting groups, among whom there were no significant differences. One Nation voters were also less accurate in their estimates of the host society's EE than LNP voters and Greens voters, with Labor voters not significantly different from any other group (Table 3).

\section{Hypothesis 3}

A one-way ANOVA revealed significant differences in perceived self-other discrepancy based on voting behaviour, $F(3,1,472)=17.87, p<.001, \eta^{2}=.04$. One Nation voters $(M=0.74 ; S D=1.14)$ and LNP voters $(M=1.11 ; S D=1.43)$ had significantly lower discrepancy scores than Labor voters $(M=1.46 ; S D=1.88)$, who in turn had significantly lower discrepancy scores than Greens voters $(M=1.95, S D=1.91)$. Perceived

Table 2

Means, Standard Deviations, and One-Way ANOVA Results Comparing Estimates of Host Society's Acculturation Expectations by Voting Behaviour

\begin{tabular}{|c|c|c|c|c|c|c|}
\hline Estimates of Host Society Expectations & Greens & Labor & LNP & One Nation & $F(3,1,472)$ & $\eta^{2}$ \\
\hline Maintenance expectations & $3.62(1.41)_{a}, \mathrm{~b}$ & $3.68(1.55)_{\text {a. b }}$ & $3.82(1.55)_{a}$ & $3.27(1.81)_{\mathrm{b}}$ & $4.23 *$ & .01 \\
\hline Embrace expectations & $5.39(1.21)_{\mathrm{c}}$ & $5.76(1.21)_{\mathrm{b}}$ & $5.88(1.21)_{\mathrm{b}}$ & $6.29(1.14)_{\mathrm{a}}$ & $15.17 * *$ & .03 \\
\hline
\end{tabular}

Note. Mean scores with different subscripts are significantly different on the basis of Tukey's HSD test.

${ }^{*} p=.005$.

${ }^{* * *} p<.001$.

(C) 2020 Asian Association of Social Psychology and John Wiley \& Sons Australia, Ltd. 
Table 3

Means, Standard Deviations, and One-Way ANOVA Results Comparing Accuracy in Estimates of Host Society's Acculturation Expectations by Voting Behaviour

\begin{tabular}{lcccccc}
\hline Accuracy in Estimates of Host Society Expectations & Greens & Labor & LNP & One Nation & $F(3,1472)$ & $\eta^{2}$ \\
\hline Maintenance expectations & $1.11(0.93)_{\mathrm{a}}$ & $1.22(1.04)_{\mathrm{a}}$ & $1.18(1.04)_{\mathrm{a}}$ & $1.60(1.11)_{\mathrm{b}}$ & $6.31^{*}$ & .01 \\
Embrace expectations & $1.02(0.65)_{\mathrm{a}}$ & $1.07(0.64)_{\mathrm{a}, \mathrm{b}}$ & $1.04(0.60)_{\mathrm{a}}$ & $1.24(0.66)_{\mathrm{b}}$ & $3.23^{* *}$ & .02 \\
\hline
\end{tabular}

Note. Mean scores with different subscripts are significantly different on the basis of Tukey's HSD test.

${ }^{*} p=.02$.

$p<.001$.

self-other discrepancy was significantly and negatively related to RWA-C $(r=-.30, p<.001)$. This suggests right-wing voters and those higher in RWA-C perceive more host society consensus with their personal expectations than left-wing voters and those lower in RWA-C. This was despite One Nation voters being typically less accurate in their estimates of host society expectations than other voters. Hypothesis 3 is supported.

\section{Hypothesis 4}

To test whether personal acculturation expectations help explain the link between RWA-C and self-other discrepancy, multiple regression analyses were conducted to assess each component of a proposed mediation model (Figure 3).

RWA-C was negatively associated with perceived selfother discrepancy for both EE, $F(1,2,011)=211.85$, $p<.001, \quad R^{2}=.10, \quad b=-.41, \quad t(2,010)=-14.56$, $p<.001$, and ME, $F(1,2,011)=85.79, p<.001, R^{2}=.04$, $b=-.30, t(2,010)=-9.26, p<.001$. RWA-C was also associated with higher personal EE, $F(1,2,011)=373.84$, $p<.001, R^{2}=.16, b=.73, p<.001$, and lower personal ME, $F(1,2,011)=69.31, p<.001, R^{2}=.03, b=-.37, t$ $(2,010)=-8.35, p<.001$. Higher personal EE was associated with lower perceived self-other discrepancy, $b=-.24$, $t(2,010)=-8.06, p<.001$, and higher personal ME was

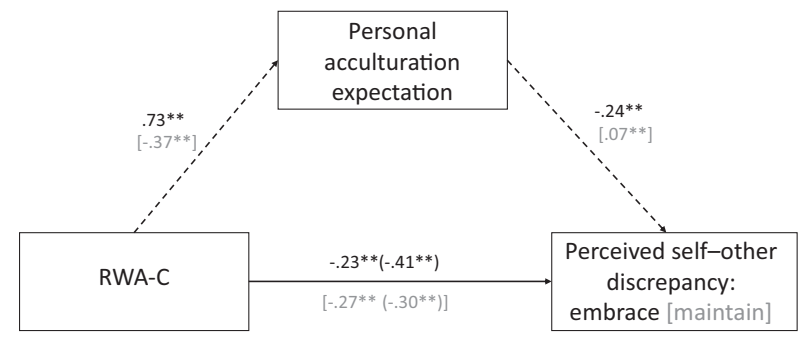

Figure 3 Indirect effect of Right-Wing Authoritarianism Conservatism on perceived self-other discrepancy, through personal acculturation expectations. Figure in parentheses indicates the total effect prior to the inclusion of the mediator. Coefficients are unstandardized. ${ }^{*} p<.05 ;{ }^{* *} p<.001$. associated with higher self-other discrepancy, $b=.07, t$ $(2,010)=4.37, p<.001$.

Mediation analyses were conducted using the bootstrapping method with bias-corrected confidence intervals (Mackinnon, Lockwood, \& Williams, 2004; Preacher \& Hayes, 2008). The 95\% confidence intervals of the indirect effects were obtained with 5,000 bootstrap samples (Preacher \& Hayes, 2008). Mediation analysis supported the hypothesised mediating role of personal acculturation expectations in the relationship between RWA-C and self-other discrepancy (EE: $b=-.17$, $\mathrm{CI}=-0.22$ to $-0.14, \quad Z=-11.98, \quad p<.001 ; \quad$ ME: $b=-.03, \mathrm{CI}=-0.04$ to $-0.01, Z=-3.85, p<.001)$, although the direct effect of RWA-C on self-other discrepancy remained significant in both cases (EE: $b=-.23, p<.001 ;$ ME: $b=-.27, t(2,010)=-8.35$, $p<.001)$. Hypothesis 4 is supported.

\section{Discussion}

Consistent with Guimond et al. (2014), we found people significantly underestimated the amount of support in their general community for the view that immigrants retain their cultural heritage and customs, and overestimated the community expectation that immigrants adopt the host society's culture. These patterns of under- and overestimation were more pronounced for those with right-wing affiliations and for those higher in RWA-C. In turn, we found evidence for a "false consensus" effect, whereby those whose personal expectations were least aligned with host society sentiment perceived greater community consensus than those whose personal attitudes more closely resembled the host society's actual attitudes.

The processes suggested by these initial findings may have important implications for mutual acculturation, specifically, immigrant-host acculturation relationships. Researchers probing the host-immigrant acculturation relationship have found that immigrants' stress and wellbeing may be detrimentally influenced where they perceive discrepancies between their own acculturation preferences and the assumed acculturation expectations 
of the host society (Kunst \& Sam, 2013; Roccas et al., 2000). If immigrants' well-being is partly predicated on perceptions of host expectations, it is critical these expectations are accurately judged. Host members who mistakenly believe their personal expectations (that immigrants embrace the host culture and forgo their originating culture) are consensually shared by the community - a false consensus effect-may be emboldened to express these expectations, confident they enjoy majority support. Conversely, host members who underestimate consensus with their view that immigrants retain their culture - a pluralistic ignorance effect - may be less likely to express their (in reality, popular) opinion (Noelle-Nuemann, 1974). Such flow-on effects may lead to faulty informational cues for the immigrant, whose perceptions of host society expectations may be derived from prominently vocalised attitudes. Over time, these false norms may even impact host society members who traditionally favour cultural maintenance, as the mere perception of discordance between immigrant preferences and host society expectations may signal trouble for social cohesion. On a broader cultural level, host society errors in social perception are ripe for exploitation by political representatives; a common rhetorical ploy of right-wing populist parties, who often have an anti-immigration, anti-multiculturalism platform, is the repeated suggestion their views represent the "silent majority" (Mols \& Jetten, 2016). This rhetoric may both foster and reinforce beliefs in those identifying with these representatives that their fringe attitudes are widely shared (Schulz, Wirth, \& Müller, 2018). Another rhetorical ploy revolves around the notion that immigration rates are threatening the numerical dominance of the majority culture; research suggests that high-RWA individuals are particularly sensitive to misperceiving actual diversity, which translates into hostile responses toward outgroups (Van Assche, Dhont, \& Pettigrew, 2019; Van Assche, Roets, Dhont, \& Van Hiel, 2016).

Our mediation pathways imply that individual-level differences (RWA-C) and personal acculturation expectations work together to influence misperceptions of others' attitudes, an assumption of directionality that cannot be validated through cross-sectional data. It is equally plausible that misperceptions of others' expectations influence one's own acculturation expectations, particularly through the reinforcing role that false consensus plays in attitude maintenance (Ross et al., 1977; Ross \& Nisbet, 1991). We conceive of the relationship between personal attitudes and perceived self-other discrepancy as bi-directional; a marginal, perhaps politically unpalatable attitude provides the stimulus for justification and belongingness (as manifest through a false consensus belief), while the false consensus in turn reinforces the legitimacy of the original attitude. Future research employing longitudinal or experimental designs could probe such causal pathways and feedback loops. For instance, to what extent does priming people with accurate information about host society expectations influence their subsequent personal expectations? These investigations might also explore whether the other dimensions of RWA (Authoritarianism and Traditionalism), and Social Dominance Orientation are also relevant for understanding self-other discrepancies, or whether different explanatory mechanisms are implicated (Grigoryev et al., 2019). Finally, we note that our "perceived self-other discrepancy" measure was calculated by comparing personal acculturation expectations with a perceived measure of a society's expectations. As such, this can be considered a proxy or inferred measure of perceived discrepancy. Future research might investigate the effects of a more direct measure of perceptions of disparity between people's own expectations and those of others, including differences between relevant subgroups (e.g., different ethnic and bicultural identities; Schwartz, Vignoles, Brown, \& Zagefka, 2014; Ward, 2006) within the host society.

Future research might also extend and refine the measures used to assess the dimensions of acculturation expectations. In the present study, we found much stronger effects for embrace expectations than maintenance expectations. This might be due to lack of specificity or clarity in the single-item measures used, a limitation of the current study. Alternatively, immigrant maintenance of cultural heritage may be relatively unimportant to those motivated by social order and consensus, providing the immigrant "fits in" with the host culture. Future research should incorporate multi-item measures of acculturation. This would help to disentangle whether the differences we observed between the two dimensions are due to psychometric limitations of a single-item measure or reflect the primary importance of the embrace dimension of acculturation expectations. Such research might also investigate whether self-other discrepancies in host community expectations differ between private and public domains of acculturation; for those who desire outgroup conformity, it may be public acculturation that is of chief concern, while the private acculturation of immigrants might be relatively unimportant. Moreover, while Berry's two-dimensional acculturation approach is widely accepted, it is also acknowledged that acculturation preferences are influenced by a range of factors, including individual characteristics, degree of identification with the heritage culture, the reasons for migrating and pre-migration circumstances, and the social and political context in which immigrants settle. It is reasonable to assume that the expectations of host community members are similarly nuanced. Replications across other cultural, political, and social contexts will help illuminate the extent to 
which the psychological mechanisms proffered here are universal or driven by context.

To conclude, we suggest the current study makes a useful and novel contribution to understanding how misperceptions of host society acculturation expectations, by host society members, may influence immigrant-host acculturation relationships and immigrant well-being.

\section{Acknowledgements}

This research was supported by Edith Cowan University (G1003405).

\section{Conflict of Interest}

The authors have no conflicts of interest to declare.

\section{References}

Arends-Tóth, J., \& van de Vijver, F. J. R. (2003). Multiculturalism and acculturation: Views of Dutch and Turkish-Dutch. European Journal of Social Psychology, 33, 249-266. https://doi.org/10.1002/ejsp.143

Australian Electoral Commission (2016). 2016 federal election. Retreived from https://www.aec.gov.au/Elections/federal_elections/ 2016/

Berry, J. W. (1997). Immigration, acculturation, and adaptation. Applied Psychology, 46, 5-34. doi:10.1111/j.1464-0597.1997.tb01087.x

Berry, J. W. (2005). Acculturation: Living successfully in two cultures. International Journal of Intercultural Relations, 29, 697-712. doi:10. 1016/j.ijintrel.2005.07.013

Berry, J. W., \& Sabatier, C. (2011). Variations in the assessment of acculturation attitudes: Their relationships with psychological wellbeing. International Journal of Intercultural Relations, 35, 658669. doi:10.1016/j.ijintrel.2011.02.002

Bourhis, R. Y., Moise, L. C., Perreault, S., \& Senécal, S. (1997). Towards an interactive acculturation model: A social psychological approach. International Journal of Psychology, 32, 369-386. doi:10. 1080/002075997400629

Duckitt, J., Bizumic, B., Krauss, S. W., \& Heled, E. (2010). A tripartite approach to right-wing authoritarianism: The authoritarianism-conservatism-traditionalism model. Political Psychology, 31, 685-715. doi:10.1111/j.1467-9221.2010.00781.x

Geiger, N., \& Swim, J. K. (2016). Climate of silence: Pluralistic ignorance as a barrier to climate change discussion. Journal of Environmental Psychology, 47, 79-90. doi:10.1016/j.jenvp.2016.05.002

Grigoryev, D., Batkhina, A., van de Vijver, F., \& Berry, J. W. (2019). Towards an integration of models of discrimination of immigrants: From ultimate (functional) to proximate (sociofunctional) explanations. Advance online publication. Journal of International Migration and Integration. doi:10.1007/s12134-019-00677-w

Grigoryev, D., van de Vijver, F., \& Batkhina, A. (2018). Discordance of acculturation attitudes of the host population and their dealing with immigrants. Journal of Intercultural Communication Research, 47, 491-509. doi:10.1080/17475759.2018.1497678

Guimond, S., de la Sablonnière, R., \& Nugier, A. (2014). Living in a multicultural world: Intergroup ideologies and the societal context of intergroup relations. European Review of Social Psychology, 25, 142-188. doi:10.1080/10463283.2014.957578

Haugen, I., \& Kunst, J. R. (2017). A two-way process? A qualitative and quantitative investigation of majority members' acculturation. International Journal of Intercultural Relations, 60, 67-82. doi:10. 1016/j.ijintrel.2017.07.004

Horenczyk, G., Jasinskaja-Lahti, I., Sam, D. L., \& Vedder, P. (2013). Mutuality in acculturation: Toward an integration. Zeitschrift Für Psychologie, 221, 205-215. doi:10.1027/2151-2604/a000150

Kruger, J. (1999). Lake Wobegon be gone! The "below-average effect" and the egocentric nature of comparative ability judgments. Journal of Personality and Social Psychology, 77, 221-232. doi:10.1037// 0022-3514.77.2.221

Kunst, J. R., \& Sam, D. L. (2013). Relationship between perceived acculturation expectations and Muslim minority youth's acculturation and adaptation. International Journal of Intercultural Relations, 37, 477-490. doi:10.1016/j.ijintrel.2013.04.007

Leong, C.-H. (2008). A multilevel research framework for the analyses of attitudes toward immigrants. International Journal of Intercultural Relations, 32, 115-129. doi:10.1016/j.ijintrel.2007.10.002

Leviston, Z., Dandy, J., Jetten, J., \& Walker, I. (2020). The role of relative deprivation in majority-culture support for multiculturalism. Journal of Applied Social Psychology, 50, 228-239. doi:10.1111/ja sp. 12652

Leviston, Z., Walker, I., \& Morwinski, S. (2013). Your opinion on climate change might not be as common as you think. Nature Climate Change, 3, 334-337. doi:10.1038/nclimate1743

Mackinnon, D. P., Lockwood, C. M., \& Williams, J. (2004). Confidence limits for the indirect effect: Distribution of the product and resampling methods. Multivariate Behavioral Research, 39, 99. doi:10.1207/s15327906mbr3901_4

Marks, G., \& Miller, N. (1987). Ten years of research on the falseconsensus effect: An empirical and theoretical review. Psychological Bulletin, 102, 72-90. doi:10.1037/0033-2909.102.1.72

Matera, C., Stefanile, C., \& Brown, R. (2015). Majority-minority acculturation preferences concordance as an antecedent of attitudes towards immigrants: The mediating role of perceived symbolic threat and metastereotypes. International Journal of Intercultural Relations, 45, 96-103. doi:10.1016/j.ijintrel.2015.02.001

Mols, F., \& Jetten, J. (2016). Explaining the appeal of populist rightwing parties in times of economic prosperity. Political Psychology, 37, 275-292. doi:10.1111/pops. 12258

Morrison, K. R., \& Matthes, J. (2011). Socially motivated projection: Need to belong increases perceived opinion consensus on important issues. European Journal of Social Psychology, 41, 707-719. doi:10. 1002/ejsp.797

Mullen, B., Atkins, J. L., Champion, D. S., Edwards, C., Hardy, D., Story, J. E., \& Vanderklok, M. (1985). The false consensus effect: A meta-analysis of 115 hypothesis tests. Journal of Experimental Social Psychology, 21, 262-283. doi:10.1016/0022-1031(85)90020-4

Navas, M., García, M. C., Sánchez, J., Rojas, A. J., Pumares, P., \& Fernández, J. S. (2005). Relative Acculturation Extended Model (RAEM): New contributions with regard to the study of acculturation. International Journal of Intercultural Relations, 29, 21-37. doi:10.1016/j.ijintrel.2005.04.001

Noelle-Nuemann, E. (1974). The spiral of silence: A theory of public opinion. Journal of Communication, 24(2), 43-51. doi:10.1111/j. 1460-2466.1974.tb00367.x 
Oyamot, C. M., Jr., Fisher, E. L., Deason, G., \& Borgida, E. (2012). Attitudes toward immigrants: The interactive role of the authoritarian predisposition, social norms, and humanitarian values. Journal of Experimental Social Psychology, 48, 97-105. doi:10.1016/j.jesp. 2011.08.003

Pedersen, A., Griffiths, B., \& Watt, S. E. (2008). Attitudes toward outgroups and the perception of consensus: All feet do not wear one shoe. Journal of Community \& Applied Social Psychology, 18, 543557. doi:10.1002/casp.964

Preacher, K. J., \& Hayes, A. F. (2008). Asymptotic and resampling strategies for assessing and comparing indirect effects in multiple mediator models. Behavior Research Methods, 40, 879-891. doi:10. 3758/BRM.40.3.879

Redfield, R., Linton, R., \& Herskovits, M. J. (1936). Memorandum for the study of acculturation. American Anthropologist, 38, 149-152. doi:10.1525/aa.1936.38.1.02a00330

Robbins, J. M., \& Krueger, J. I. (2005). Social projection to ingroups and outgroups: A review and meta-analysis. Personality and Social Psychology Review, 9, 32-47. doi:10.1207/s15327957pspr0901_3

Roccas, S., Horenczyk, G., \& Schwartz, S. (2000). Acculturation discrepancies and well-being: The moderating role of conformity. European Journal of Social Psychology, 30, 323-334. doi:10.1002/ (SICI)1099-0992(200005/06)30:3<323: : AID-EJSP992>3.0.CO;2-5

Rohmann, A., Piontkowski, U., \& van Randenborgh, A. (2008). When attitudes do not fit: Discordance of acculturation attitudes as an antecedent of intergroup threat. Personality and Social Psychology Bulletin, 34, 337-352. doi:10.1177/0146167207311197

Ross, L., Greene, D., \& House, P. (1977). The "false consensus effect": An egocentric bias in social perception attribution processes. Journal of Experimental Social Psychology, 13, 279-301. doi:10.1016/00221031(77)90049-X

Ross, L., \& Nisbet, R. (1991). The person and the situation: Perspectives of social psychology. London, UK: McGraw-Hill.

Sanders, G. S., \& Mullen, B. (1983). Accuracy in perceptions of consensus: Differential tendencies of people with majority and minority positions. European Journal of Social Psychology, 13, 5770. doi:10.1002/ejsp.2420130104

Schulz, A., Wirth, W., \& Müller, P. (2018). We are the people and you are fake news: A social identity approach to populist citizens' false consensus and hostile media perceptions. Communication Research, 47, 201-226. doi:10.1177/0093650218794854

Schwartz, S., Vignoles, V. L., Brown, W., \& Zagefka, H. (2014). The identity dynamics of acculturation and multiculturalism. In V. Benet-
Martínez, \& Y. Y. Hong (Eds.), The Oxford handbook of multicultural identity (pp. 57-92). Oxford, UK: Oxford University Press. doi:10.1093/oxfordhb/9780199796694.013.014

Shamir, J., \& Shamir, M. (1997). Pluralistic ignorance across issues and over time: Information cues and biases. Public Opinion Quarterly, 61, 227-260. doi:10.1086/297794

Strube, M. J., \& Rahimi, A. M. (2006). "Everybody knows it's true": Social dominance orientation and right-wing authoritarianism moderate false consensus for stereotypic beliefs. Journal of Research in Personality, 40, 1038-1053. doi:10.1016/j.jrp.2005.10.004

Suls, J., Wan, C. K., \& Sanders, G. S. (1988). False consensus and false uniqueness in estimating the prevalence of health-protective behaviors. Journal of Applied Social Psychology, 18, 66-79. doi:10. 1111/j.1559-1816.1988.tb00006.x

Thomsen, L., Green, E. G. T., \& Sidanius, J. (2008). We will hunt them down: How social dominance orientation and right-wing authoritarianism fuel ethnic persecution of immigrants in fundamentally different ways. Journal of Experimental Social Psychology, 44, 1455-1464. doi:10.1016/j.jesp.2008.06.011

Van Assche, J., Dhont, K., \& Pettigrew, T. F. (2019). The socialpsychological bases of far-right support in Europe and the United States. Journal of Community \& Applied Social Psychology, 29, 385-401. doi:10.1002/casp.2407

Van Assche, J., Roets, A., Dhont, K., \& Van Hiel, A. (2016). The association between actual and perceived ethnic diversity: The moderating role of authoritarianism and implications for outgroup threat, anxiety, and mistrust. European Journal of Social Psychology, 46, 807-817. doi:10.1002/ejsp.2211

Ward, C. (2006). Acculturation, identity and adaptation in dual heritage adolescents. International Journal of Intercultural Relations, 30, 243-259. doi:10.1016/j.ijintrel.2005.09.001

Ward, C., \& Masgoret, A.-M. (2018). Attitudes toward immigrants, immigration, and multiculturalism in New Zealand: A social psychological analysis. International Migration Review, 42, 227-248. doi:10.1111/j.1747-7379.2007.00119.x

Watt, S. E., \& Larkin, C. (2010). Prejudiced people perceive more community support for their views: The role of own, media, and peer attitudes in perceived consensus. Journal of Applied Social Psychology, 40, 710-731. doi:10.1111/j.1559-1816.2010.00594.x

Zagefka, H., \& Brown, R. (2002). The relationship between acculturation strategies, relative fit and intergroup relations: Immigrant-majority relations in Germany. European Journal of Social Psychology, 32, 171-188. doi:10.1002/ejsp.73 